\title{
Matrix Effect Studies in the GFAAS Determination of Magnesium in Proposed Fuel for Indian Advance Heavy Water Reactor (AHWR)
}

\author{
Santosh Kumar Gupta, Neelam Goyal*, and S.V. Godbole \\ Radiochemistry Division, Bhabha Atomic Research Centre \\ Trombay, Mumbai - 400 085, India
}

\section{INTRODUCTION}

Atomic absorption spectrometry, utilizing an electrically heated graphite furnace as atomization device, has proved to be a very successful method for the direct determination of a number of important trace elements in nuclear materialbased samples (1). An approach based on the atomization of the analytes in the presence of the major matrix is a welcome step as it eliminates quantitative chemical separation and preconcentration of the analytes and the associated possible sample contamination either from extensive handling or due to addition of various reagents. Due to the very high sensitivity of graphite furnace atomic absorption spectrometry (GFAAS), a fraction of a milligram of sample is required to permit determination of the analytes at ppm levels. Quality control of $\mathrm{U}+\mathrm{Th}$ is essential since $\mathrm{U}+\mathrm{Th}$ is the proposed fuel for the 3rd generation Advance Heavy Water Reactor (AHWR) (2).

Magnesium is one of the specification elements in U+Th fuel because (a) it increases the sintered density of thoria, (b) it brings down the sintering temperature of thoria, and (c) it aids in the dissolution of thoria (3). Its incorporation in the thoria lattice generates oxygen vacancies. However, if present above certain specified concentrations, Mg dilutes the fuel. Its specification in thoria powder is $50 \mathrm{ppm}$ maximum which makes it imperative to determine $\mathrm{Mg}$ in AHWR nuclear fuels.

*Corresponding author.

E-mail: neelam@barc.gov.in

\section{ABSTRACT}

Studies on the atomization of $\mathrm{Mg}$ in U+Th matrix were carried out and the effect of matrix composition on analyte absorbance was investigated using graphite furnace atomic absorption spectrometry (GFAAS). These studies showed that the absorbance signal for $\mathrm{Mg}$ in mixed matrices is reduced in comparison to matrixfree solutions. The variation in the GFAAS absorbance signal of $\mathrm{Mg}$ as a function of increase in matrix concentration and matrix composition was studied and found to affect $\mathrm{Mg}$ absorbance.

Based on these investigations, analytical methods were developed for the direct determination of $\mathrm{Mg}$ in aqueous and in the presence of $0.1 \mathrm{mg} / \mathrm{mL}$ ( $3 \% \mathrm{U}+\mathrm{Th})$ solution ranging from $0.004-0.1$ and $0.004-0.08 \mu \mathrm{g} / \mathrm{mL}$, respectively. Buildup of the matrix within the atomizer over its repetitive use did not cause any significant changes in the absorbance signals up to 100 atomization cycles. In the presence of 20 common metallic elements (Ag, Al, B, Be, $\mathrm{Ca}, \mathrm{Cd}, \mathrm{Co}, \mathrm{Cr}, \mathrm{Cu}, \mathrm{Fe}, \mathrm{Mn}, \mathrm{Mo}$, $\mathrm{Na}, \mathrm{Ni}, \mathrm{Pb}, \mathrm{Si}, \mathrm{Sn}, \mathrm{V}, \mathrm{W}$, and $\mathrm{Zn}$ ) in the sample, there was no significant interference on the $\mathrm{Mg}$ signals.

The performance of the method was evaluated by analyzing synthetic samples. It was found that sample and standard solutions must contain the same concentration of $\mathrm{U}+\mathrm{Th}$ matrix. The significant suppression in the absorbance signal for $\mathrm{Mg}$ in the presence of the matrix is also discussed. The analytical procedure developed can be applied to the rapid analysis of $\mathrm{U}+\mathrm{Th}$ samples without pretreatment such as separation and preconcentration of matrix.
A number of reports have been published on the use of atomic spectroscopic methods for trace metal assay of uranium (4-5), plutonium (6-7), and thorium (8-10) matrices. Inductively coupled plasma optical emission spectrometry (ICP-OES) is an ideal technique for the simultaneous multi-element determination at trace levels with good sensitivity. However, due to the low tolerance for dissolved solids, the detection limits obtained in the direct determination of trace elements often do not meet the requirement. The optical emission spectrometric (OES) technique with D.C. arc excitation source also requires physical separation procedures with the help of a suitable carrier (11). In addition, OES methods require larger sample sizes but the availability of many biological samples in ample quantity for biomedical investigations is sometimes very limited. Use of a two-jet plasma optical emission spectrometric technique for the determination of $\mathrm{Mg}$ in whole blood has been reported (12).

Among the instrumental techniques available, graphite furnace atomic absorption spectrometry (GFAAS) is still one of the most widely used techniques for trace metal determination. The high sensitivity and relative freedom from spectral interferences makes it suitable for determining trace constituents in the presence of milligram amounts of matrix material without chemical separation and preconcentration steps. GFAAS has been widely used for the quantitative determination of $\mathrm{Mg}$ in various matrices such as uranyl nitrate and uranium oxide (13-14) as well as in food and water samples in combi- 
nation with magnesium hydroxide coprecipitation (15).

The use of electrothermal AAS for the determination of $\mathrm{Mg}$ has been reported for drinking water (16); multimineral and multivitamin preparations, and pharmaceutical raw materials (17); and for preparations made from peppermint and nettle leaves (18).

Flame atomic absorption spectrometry (FAAS) is utilized for routine analysis of $\mathrm{Mg}$ in matrices such as thorium-based nuclear material (19), biodiesel samples (20-21), emulsified chocolate samples (22), and fish species (23). It can also be employed for determining the concentration and bioavailability of $\mathrm{Mg}$ in ripened bee honey (24), emulsified egg samples (25), xylem sap using a micro-sampling technique (26), buffalo milk (27), the magnesium metabolism of patients (28), lubricating oils (29), and lung carcinomatous tissues (30).

However, in this study we investigated the application of GFAAS for the direct determination of $\mathrm{Mg}$ in the presence of a 3\% U+Th matrix. The effects of different amounts of $U$ ranging from $0-10 \%$ in a U+Th matrix, the residual buildup of the matrix in the graphite furnace (GF) and in the presence of other metallic elements on $\mathrm{Mg}$ absorbance have been studied. The results obtained helped to understand the change in the analyte absorbance signal with a change in the matrix.

\section{EXPERIMENTAL}

\section{Instrumentation}

A GBC-906 atomic absorption spectrometer, equipped with a GF 3000 graphite furnace atomizer and a programmable sample dispenser, was used for the determination of $\mathrm{Mg}$ in a U+Th matrix (GBC Scientific Equipment Pty, Ltd., Australia). The graphite furnace was pyrolytically coated and atomization was performed with the sample loaded inside the tube. A deuterium lamp with a sampling frequency of 200 $\mathrm{Hz}$ was used for background correction. An Eppendorf micropipette $(5 \mu \mathrm{L}$ volume $)$ with PTFE tips was used for dispensation of the samples into the graphite furnace. The instrumental parameters are listed in Table I.

All measurements were carried out in peak height mode. Ramp mode of heating at $2000{ }^{\circ} \mathrm{C} / \mathrm{s}$ was used. Details of the sample preparations and procedures followed are given elsewhere (9). The fundamental conditions of GFAAS analysis such as temperature and time at the pre-atomization and atomization steps were investigated in order to establish the optimum conditions for obtaining stable and sensitive atomic absorbance signals for $\mathrm{Mg}$ in a 3\% U+Th matrix, as well as in a matrix-free solution. In the present work, the less sensitive spectral line of $202.5 \mathrm{~nm}$ was used for absorbance measurements. The most sensitive line of $285.2 \mathrm{~nm}$ was

\section{TABLE I \\ Instrumental \\ Parameters Used for Mg With the GF-3000 AAS}

\begin{tabular}{lr}
\hline Wavelength & $202.5 \mathrm{~nm}$ \\
Spectral Bandwidth & $0.5 \mathrm{~nm}$ \\
Lamp Fill Gas & $\mathrm{Ne}$ \\
Lamp Current & $10 \mathrm{~mA}$ \\
Gas used & $\mathrm{Ar}$ \\
Flow rate & $6 \mathrm{~L} / \mathrm{min}$ \\
\hline
\end{tabular}

found to be unsuitable since the quartz double distilled (Q.D.D.) water containing $\sim 5 \mathrm{ng} / \mathrm{mL} \mathrm{Mg}$ gave an absorbance of $\sim 2.5$.

The following experiments were carried out for $\mathrm{Mg}$ :

\section{Effect of matrix on absorbance}

(a) Using a fixed concentration of $\mathrm{Mg}$, the absorbance was monitored as a function of matrix concentration ranging from $0-1.0 \mathrm{mg} / \mathrm{mL}$. (b) The Mg absorbance was monitored as a function of matrix composition by using a fixed concentration of $\mathrm{Mg}$ and a matrix with uranium concentrations ranging from $0-10 \%$ U/U+Th. (c) The characteristic concentration for $\mathrm{Mg}$ was obtained by analyzing two sets of standards: one using an aqueous solution and one using a 3\% U+Th solution each with different amounts of $\mathrm{Mg}$.

\section{Effect of matrix on signal appear-} ance temperature $\left(T_{a p p}\right)$ and determination of activation energies for $\mathrm{Mg}$ atom formation

$\mathrm{T}_{\text {app }}$ was obtained by varying the temperature in the atomization stage and measuring the absorbance at a fixed $\mathrm{Mg}$ concentration. The lowest temperature where a detectable signal was obtained above the blank signal was taken as appearance temperature (31) in the aqueous and the U+Th matrix. For a fixed concentration of $\mathrm{Mg}$, the atomization temperature was varied from $\mathrm{T}_{\text {app }}$ onwards, and a logarithm plot of the absorbance as a function of the inverse of the absolute temperature was obtained. This should yield a straight line, and the slope of such an Arrehenius plot would give the activation energy. The procedure was repeated for the aqueous and the U+Th matrix.

The activation energies were, in turn, compared with the thermodynamic data from the literature (32) to infer the final mode of atomization. 


\section{RESULTS AND DISCUSSION}

Earlier studies with GFAAS on the determination of $\mathrm{Mg}$ reported that the absorbance signals in uranium $(13,14)$ and thorium (19) are quite different from those of matrix-free solutions. Matrix effect studies, therefore, form an essential feature of all methods based on a direct determination approach. A study on the atomization of $\mathrm{Mg}$ in a matrix-free solution, as well as in a U+Th matrix, was carried out.

The GFAAS measurement parameters, such as pre-atomization temperature and atomization temperatures and time, are very important in order to obtain precise and sensitive atomic absorbance measurements. For optimization of these parameters (pre-atomization and atomization temperature) on the absorbance of $\mathrm{Mg}$ in aqueous nitrate solutions, the effects of the temperatures ranging from $400-900{ }^{\circ} \mathrm{C}$ and $1900-3000^{\circ} \mathrm{C}$, respectively, were studied. The preatomization temperature is not very critical for $\mathrm{Mg}$ because $\mathrm{Mg}\left(\mathrm{NO}_{3}\right)_{2}$ decomposes at $477^{\circ} \mathrm{C}$ (33) to its oxide $(\mathrm{MgO})$. The melting and boiling points of $\mathrm{MgO}$ (32) are high and, hence, pre-atomization losses are not expected. It was found that the absorbance of $\mathrm{Mg}$ remained constant with the pre-atomization temperatures ranging from 400 to $900^{\circ} \mathrm{C}$. Therefore, $500^{\circ} \mathrm{C}$ was used for pre-atomization. Studies of the atomization behavior in the 1700 to $2800{ }^{\circ} \mathrm{C}$ range showed that the optimum temperature for atomization was $2600{ }^{\circ} \mathrm{C}$.

The effect of pre-atomization temperature on the absorbance of $\mathrm{Mg}$ was also investigated in the presence of $U+T h$ matrix in the 400 to $900{ }^{\circ} \mathrm{C}$ range. It was found that the absorbance remained constant at and above $700{ }^{\circ} \mathrm{C}$. Using a lower temperature resulted in a higher non-specific absorbance signal. Possible non-specific absorbance from the U+Th matrix using a $\mathrm{H}_{2}$ continuum lamp was found to be negligible for $\mathrm{Mg}$.

The atomization behavior was studied in the temperature range of 2000 to $2800{ }^{\circ} \mathrm{C}$. It was found that constant and maximum absorbance was obtained at 2600 to $2700{ }^{\circ} \mathrm{C}$.

Based on these observations, the pre-atomization and atomization temperatures and time durations selected for $\mathrm{Mg}$ were $700{ }^{\circ} \mathrm{C} / 30 \mathrm{~s}$ and $2600{ }^{\circ} \mathrm{C} / 0.3 \mathrm{~s}$, respectively. Details of the optimized experimental parameters are listed in Table II.

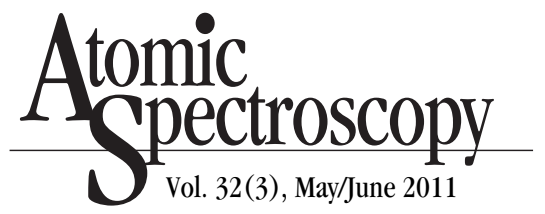

Effect of matrix concentration

A systematic reduction in the absorbance signal was reported (13) for Mg with a progressive increase in $\mathrm{U}$ concentration up to $20 \mathrm{mg} / \mathrm{mL}$. A study on the atomization of $\mathrm{Mg}$ in matrix-free solutions as well as in the U+Th matrix was, therefore, carried out. The variation obtained in the GFAAS absorbance signal of $\mathrm{Mg}$ as a function of matrix concentration is shown in Figure 1. As can be seen, there is a significant suppression in the absorbance signal with an increase in matrix concentration from $0-1.0 \mathrm{mg} / \mathrm{mL}$.

TABLE II

Optimized Experimental Parameters for $\mathrm{Mg}$ in Aqueous and in 3\% $\mathrm{U}+\mathrm{Th}$ Matrix

\begin{tabular}{ccc|ccc}
\hline \multicolumn{4}{c}{ Graphite Furnace Atomizer Settings } \\
\hline \multicolumn{3}{c}{ Aqueous Matrix } & \multicolumn{3}{c}{ 3\% U+Th Matrix } \\
\hline Temp. & \multicolumn{2}{c}{ Time (sec.) } & Temp. & \multicolumn{2}{c}{ Time (sec.) } \\
$\left({ }^{\circ} \mathrm{C}\right)$ & Ramp & Hold & $\left({ }^{\circ} \mathrm{C}\right)$ & Ramp & Hold \\
\hline 80 & 10 & 10 & 80 & 10 & 10 \\
120 & 5 & 20 & 120 & 5 & 20 \\
500 & 5 & 30 & 700 & 5 & 30 \\
2600 & 1.1 & 0.3 & 2600 & 1.0 & 0.3 \\
20 & 14.5 & 0.5 & 20 & 14.5 & 0.5 \\
\hline
\end{tabular}

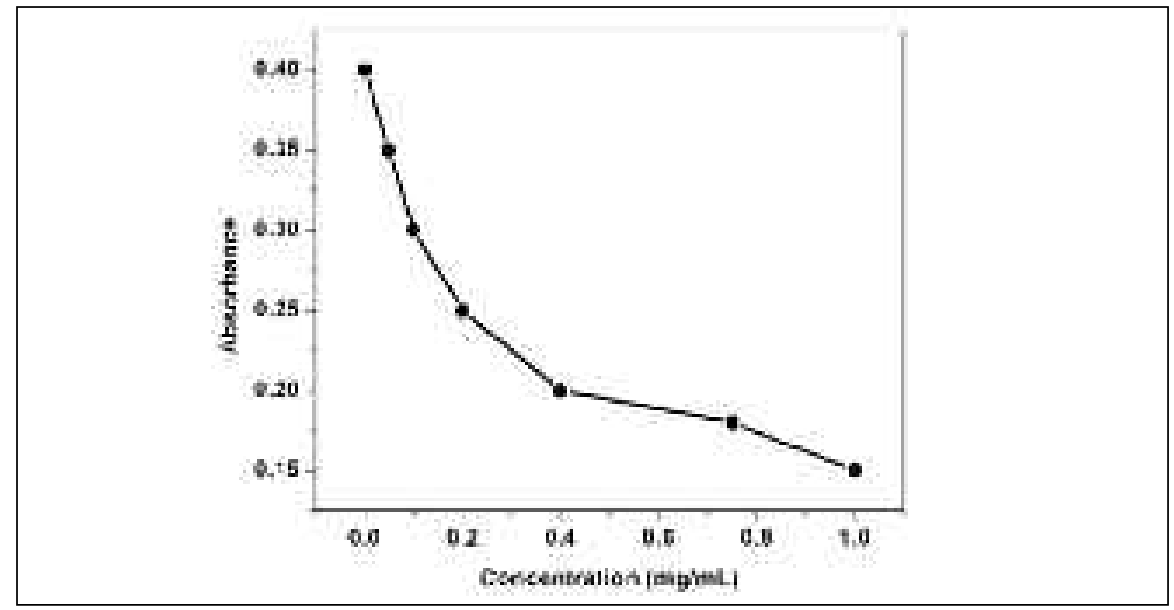

Fig. 1. Effect of matrix concentration on absorbance of $\mathrm{Mg}$. 
Figure 2 shows the peak profiles plotted at $0.03 \mu \mathrm{g} / \mathrm{mL} \mathrm{Mg}$ for three different matrix concentrations: 0 (aqueous), $0.1 \mathrm{mg} / \mathrm{mL}$ and $0.4 \mathrm{mg} / \mathrm{mL}$. It can be seen that the peak profile broadens, and peak height and peak area reduces with an increase in matrix concentration.

A systematic reduction in the absorbance signal was observed with a progressive increase in $\mathrm{U}+\mathrm{Th}$ matrix concentrations ranging from $0-1.0 \mathrm{mg} / \mathrm{mL}$. This indicates a suppressive interference due to the U+Th matrix. To meet the $\mathrm{Mg}$ specification limit of 50 ppm set for AHWR fuel, the matrix concentration was kept at $0.1 \mathrm{mg} / \mathrm{mL}$ for further studies. The suppression in $\mathrm{Mg}$ absorbance with $0.1 \mathrm{mg} / \mathrm{mL} \mathrm{U}+$ Th matrix was found to be almost 2.5 times that of the matrix-free solution.

\section{Effect of matrix composition}

Having fixed the matrix concentration, the effect of matrix composition was studied by varying the uranium percentage in the $\mathrm{U}+\mathrm{Th}$ matrix from $0-10 \%$ and keeping the total matrix concentration at $0.1 \mathrm{mg} / \mathrm{mL}$. As can be seen from Figure 3, with an increase in $\% \mathrm{U} / \mathrm{U}+\mathrm{Th}$ matrix, the Mg absorbance is marginally affected at $2-4 \% \mathrm{U}$ concentration, while a suppression of $\sim 50 \%$ was found at $10 \% \mathrm{U} / \mathrm{U}+\mathrm{Th}$, the maximum \% $\mathrm{U}$ investigated in the present work. The suppression in absorbance with an increase in $\% \mathrm{U} / \mathrm{U}+\mathrm{Th}$ can be correlated to the change in $\mathrm{pO}_{2}$ in the atomizer due to the thermal decomposition of the uranium oxide. Release of [O] from uranium oxide results (6) in a decrease in the rate of $\mathrm{Mg}$ atomization. Hence, suppression in $\mathrm{Mg}$ absorbance was observed with an increase in the \% of $\mathrm{U}$ in the $\mathrm{U}+\mathrm{Th}$ matrix. Thermo-gravimetric (34) studies for $\mathrm{ThO}_{2}-2 \% \mathrm{U}_{3} \mathrm{O}_{8}$ granules also showed a continuous decrease in weight at the temperatures ranging from 400 to $1500{ }^{\circ} \mathrm{C}$.
The weight loss is mainly attributed to a release of oxygen from $\mathrm{U}_{3} \mathrm{O}_{8}$.

Successive loading of U+Th samples and standards leads to a matrix buildup inside the graphite tube. However, this buildup did not have any significant effect on the $\mathrm{Mg}$ absorbance with repetitive loading of the $0.1 \mathrm{mg} / \mathrm{mL}$ matrix in the same atomizer. The absorbance remained constant with repetitive loading of the sample up to 100 atomization cycles.
Using the optimized parameters, a method was developed for the direct determination of $\mathrm{Mg}$ in a $3 \%$ $\mathrm{U}+\mathrm{Th}$ matrix. The AHWR is expected to use fuel consisting of a solid solution of (U-Th) $\mathrm{O}_{2}$ containing 3-4\% U. Thus, the analytical method developed here with 3\% U in a U+Th matrix can be applied directly to the analysis of AHWR fuel. The blank contribution from the matrix for $\mathrm{Mg}$ is very high and, hence, the blank subtracted data was used. The linear analytical ranges in the presence and absence of the matrix were obtained and

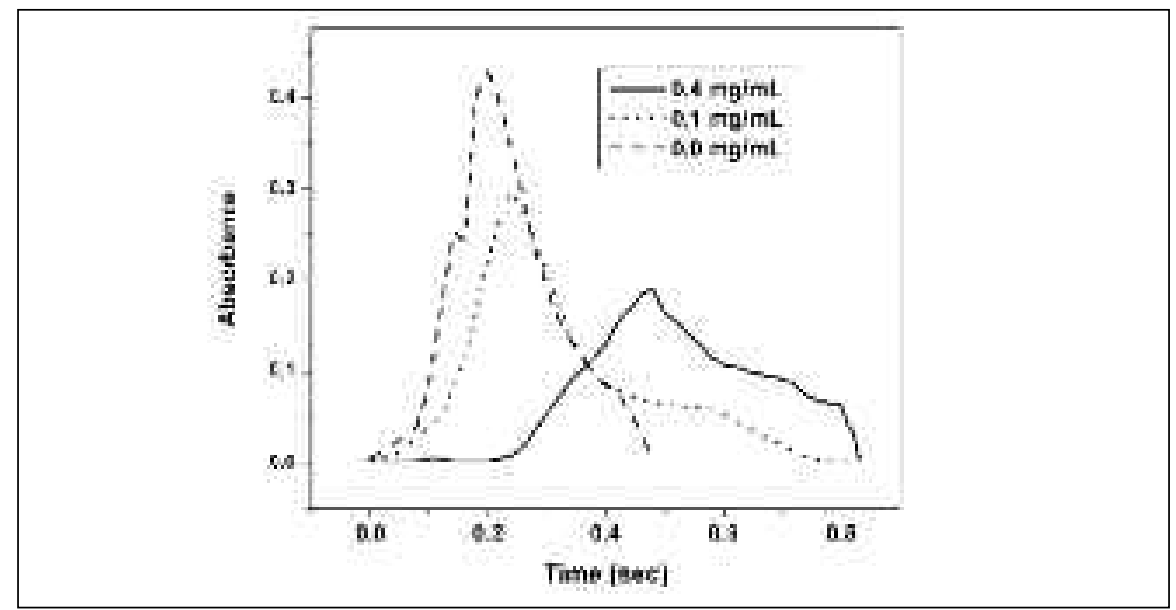

Fig. 2. Peak profile variation with an increase in matrix concentration.

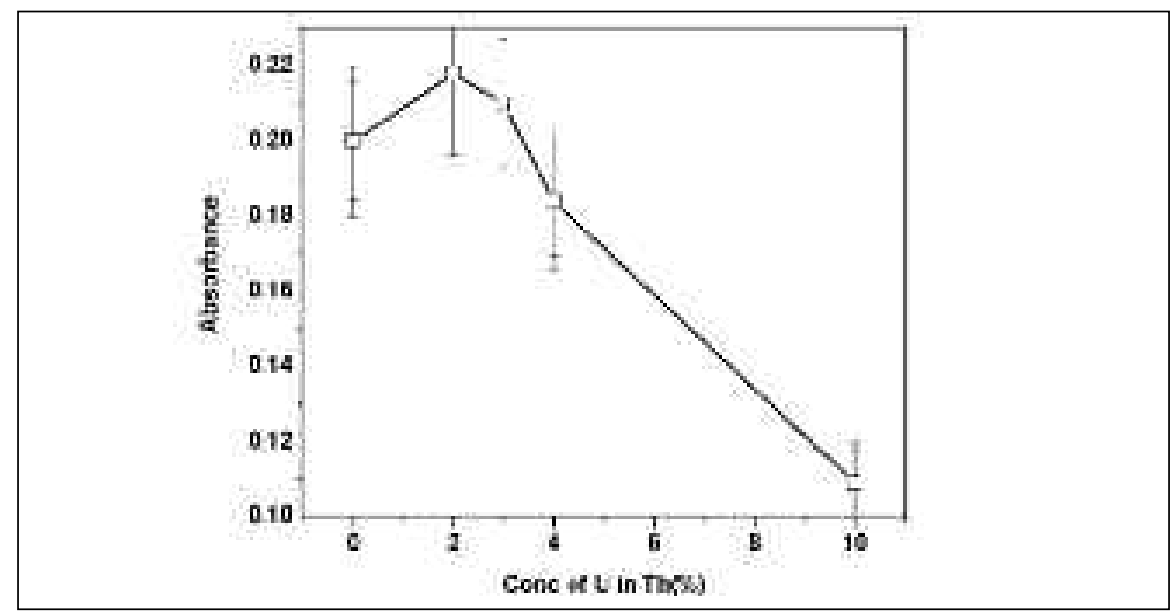

Fig. 3. Effect of \%U on Mg in mixed $U+T h$ matrix. 


\section{Atomic Spectroscopy \\ $\bigcup$ Vol. 32(3), May/June 2011}

are shown in Figure 4. A suppression in the magnitude of $\mathrm{Mg}$ absorbance was observed in the presence of $0.1 \mathrm{mg} / \mathrm{mL}$ matrix (3\% $\mathrm{U}+\mathrm{Th}$ ) as compared to a matrix-free solution.

The characteristic concentration values and the lowest amount of $\mathrm{Mg}$ determined in the presence of an aqueous and a $U+T h$ matrix are listed in Table III. As can be seen, $\mathrm{Mg}$ shows a reduction in sensitivity in the matrix as compared to the aqueous solution.

The performance of the above method was evaluated by analyzing a synthetic sample containing $\mathrm{Mg}$ in the 3\% U+Th matrix with concomitant impurities (see Table IV). The precision obtained in the analysis of three synthetic samples was found to be better than $8 \%$ RSD. The effect of the presence of concomitant impurities, therefore, is considered to be negligible within experimental errors. The data obtained from the above studies reveal that $\mathrm{Mg}$ can be determined at $0.004 \mu \mathrm{g} / \mathrm{mL}$ using a $5-\mu \mathrm{L}$ sample solution in the presence of $0.1 \mathrm{mg} / \mathrm{mL} \mathrm{3 \%} \mathrm{U+Th} \mathrm{matrix.} \mathrm{These}$ studies clearly indicate the importance of establishing prior knowledge of the matrix concentration before applying the method for the direct determination of these analytes.

The method developed here was utilized for the rapid analysis of real samples without prior separation of the matrix. The results obtained are listed in Table V.

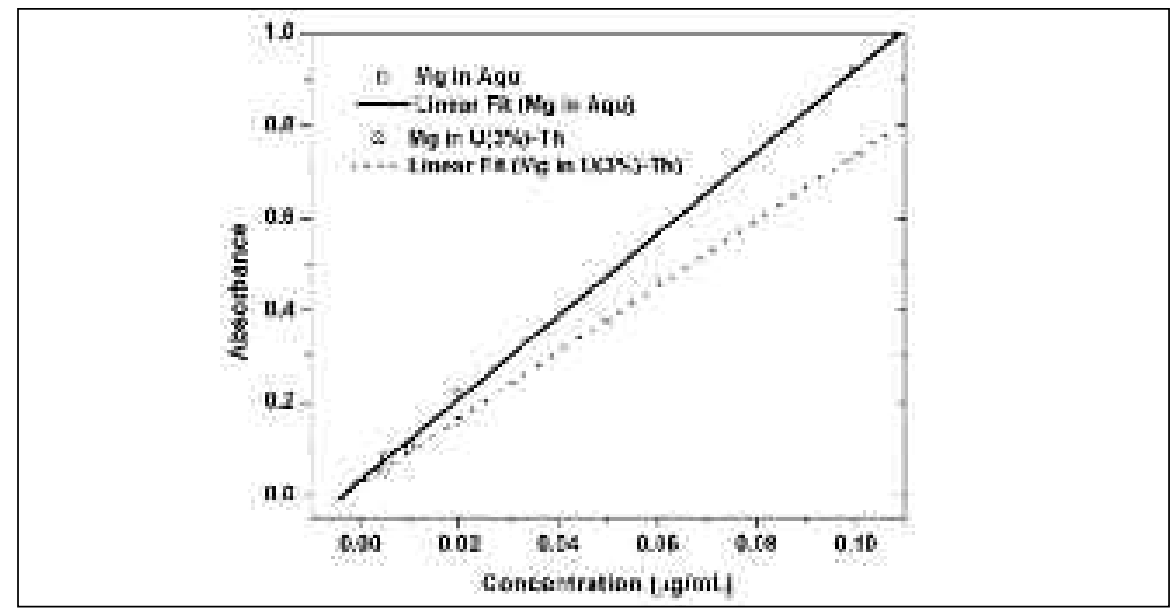

Fig.4. Analytical curves for Mg in aqueous and in U+Th matrix.

TABLE III

Characteristic Concentrations (C.C.), the Smallest Amount

Determined and Analytical Range for Mg in 3\% U+Th Matrix

\begin{tabular}{l|c|lc|cc}
\hline \multicolumn{1}{c|}{ Matrix } & $\begin{array}{c}\text { C. C. } \\
(\mathrm{ng} / \mathrm{mL})\end{array}$ & \multicolumn{2}{|c|}{$\begin{array}{l}\text { Linear Analytical Range } \\
(\mu \mathrm{g} / \mathrm{mL})\end{array}$} & \multicolumn{2}{|c}{ LOQ $^{\mathrm{b}}(\mathrm{ppm})$} \\
Present & $\begin{array}{c}\text { Reported } \\
(13)\end{array}$ \\
\hline Aqueous & 0.459 & $0.004-0.1$ & - & $20 \times 10^{-12}$ & $25 \times 10^{-12}$ \\
U+Th & 0.600 & $0.004-0.08$ & $40-800$ & $20 \times 10^{-12}$ & - \\
\hline
\end{tabular}

a On the basis of $0.1 \mathrm{mg} / \mathrm{mL}$ of matrix. $\quad{ }^{b}$ LOQ=Limits of Quantification.

TABLE IV

Analytical Results Obtained for Mg in the Presence of 3\% U+Th Matrix Using the Optimized Experimental Parameters (ppm)

\begin{tabular}{c|c|rrrrr}
\hline Matrix & Mg Amount & \multicolumn{5}{|c}{ Mg Concentrations $^{\text {Oddained }}{ }^{\mathrm{a}}$} \\
& Added & 1 & 2 & \multicolumn{1}{c}{3} & 4 & 5 \\
\hline U+Th & 75 & 70 & 68 & 80 & 69 & 81 \\
U+Th & 100 & 96 & 105 & 107 & 95 & 103 \\
U+Th & 200 & 210 & 198 & 205 & 189 & 208 \\
\hline
\end{tabular}

${ }^{a}$ Five different analyses of each sample of $\mathrm{Mg}(75,100$, and $200 \mathrm{ppm})$ to evaluate the performance of the method.

TABLE V

Synthetic Sample Analysis for Mg in 3\% U+Th Matrix Amount Expected Amount Determined

$700 \mathrm{ppm}$ 710 ppm 
To understand the suppression of $\mathrm{Mg}$ absorbance in the presence of the matrix, the reaction mechanism involved in the atomization of $\mathrm{Mg}$ in the presence and absence of the matrix was studied using the Arrehenius plots of $\ln (\mathrm{A}) \mathrm{vs}$. $\mathrm{T}^{-1}$. The slope of the plot is equal to $-\mathrm{E}_{\mathrm{a}} / \mathrm{R}$, where $\mathrm{E}_{\mathrm{a}}$ is the activation energy. The studies carried out here include the determination of $\mathrm{T}_{\mathrm{app}}$ and $\mathrm{E}_{\mathrm{a}}$ for the atom formation in both solutions. Signals $\mathrm{T}_{\mathrm{app}}$ and $E_{a}$ were found to be the same in both the aqueous and the $\mathrm{U}+\mathrm{Th}$ matrix, i.e., independent of the matrix. The values are listed in Table VI. It was also found that the $E_{a}$ values were independent of the analyte mass atomized.

A comparison of the $T_{a p p}$ and $E_{a}$ values obtained in the present study with those reported in the literature (32) for the aqueous medium shows good agreement between the two values. It has been established that on the surface of a graphite atomizer, carbon participates not only in the formation of the carbides of the elements (35) but also in the reduction of the oxides of the free metal (36). It has also been reported that when a mixture of magnesium nitrate is heated with graphite powder (37) to a temperature of $1097^{\circ} \mathrm{C}$, no reaction effects are observed, and the preferred mode of $\mathrm{Mg}$ atomization is the dissociation of $\mathrm{MgO}$ on vaporization (32), not on carbothermic reduction. The mode of atomization for $\mathrm{Mg}$ in the $\mathrm{U}+\mathrm{Th}$ matrix as well as in the aqueous solution essentially remained the same. The suppression in the absorbance signal in the presence of the matrix, therefore, cannot be ascribed to any change in the reaction mechanism. The suppression may be the result of entrapment of $\mathrm{MgO}$ in the stable lattice of the mixed oxide $\left(3 \% \mathrm{UO}_{2}+97 \% \mathrm{ThO}_{2}\right)$ prior to its atomization.

TABLE VI

Appearance Temperatures and Activation Energies for $\mathrm{Mg}$

\begin{tabular}{c|cc|cc}
\hline Mg & \multicolumn{2}{|c|}{$\begin{array}{c}\text { Appearance Temperature } \\
\mathrm{T}_{\mathrm{app}}(\mathrm{K})\end{array}$} & \multicolumn{2}{c}{$\begin{array}{c}\text { Activation Energy } \\
\mathrm{E}_{\mathrm{a}}(\mathrm{Kcal} / \mathrm{mol})\end{array}$} \\
\hline & Obtained & $\begin{array}{c}\text { Reported } \\
(32)\end{array}$ & Obtained & $\begin{array}{c}\text { Reported } \\
\text { (32) }\end{array}$ \\
\hline Aqueous & 1600 & 1510 & $173 \pm 10$ & $158 \pm 10$ \\
$3 \% \mathrm{U}+\mathrm{Th}$ & 1600 & - & $170 \pm 10$ & \\
\hline
\end{tabular}

\section{CONCLUSION}

Atomic absorption spectrometric methods using graphite furnace (GFAAS) are described for the direct determination of $\mathrm{Mg}$ in aqueous and $\mathrm{U}+\mathrm{Th}$ solutions, including the matrix effects on magnesium in GFAAS analysis. A systematic reduction in the absorbance signal was observed with a progressive increase in the $\mathrm{U}+\mathrm{Th}$ matrix concentration from $0-1.0 \mathrm{mg} / \mathrm{mL}$. It was found that an increase in the \%U/U+Th matrix from $2-4 \% \mathrm{U}$ only marginally affects Mg absorbance.

A method was developed for the direct determination of $\mathrm{Mg}$ in a $3 \%$ $\mathrm{U}+\mathrm{Th}$ matrix which is the fuel expected to be used for the 3rd generastion Advance Heavy Water Reactor (AHWR) [solid solution of (U-Th) $\mathrm{O}_{2}$ containing 3-4\% U]. The GFAAS method was optimized and found to be applicable for the direct determination of $\mathrm{Mg}$ at $0.004 \mu \mathrm{g} / \mathrm{mL}$ in a $0.1 \mathrm{mg} / \mathrm{mL} \mathrm{U}+\mathrm{Th}$ sample. The analytical range of $\mathrm{Mg}$ in the matrix is adequately low to meet the specification limits. In addition, no chemical modifier for enhancing the analyte signal was required. It should be noted that appropriate matching of the $\mathrm{U}+\mathrm{Th}$ content in the standards and samples is a prerequisite.

$\overline{\text { Received March 31, } 2011}$

\section{REFERENCES}

1. Neelam Goyal, P.J. Purohit and S V. Godbole, At. Spectrosc. 31(6) 190 (2010), (and reference therein).

2. R. K. Sinha and Anil Kakodkar; Nuclear Engineering and Design, 236, 683 (2006).

3. P. Balakrishna et al., J. of Mat. Sci. Lett. 7, 657 (1988).

4. Neelam Goyal, Paru J. Purohit, Madhuri J. Kulkarni, and S. V. Godbole, At. Spectrosc. 30, 156 (2009), (and reference therein).

5. A.A Argekar, M.J. Kulkarni, J.N. Mathur, and A.G. Page, Talanta 42, 1937 (1995).

6. Neelam Goyal, Renu Agarwal, Paru J. Purohit and S. V. Godbole, Journal of Nucl. Materials 376, 119 (2008).

7. A.A. Argekar, M.J. Kulkarni, J.N. Mathur, and A.G. Page, Talanta 56, 59 (2002).

8. N. K. Porwal, A. A. Argekar, P. J. Purohit, A. G. Page and M. D. Sastry, Fr. Z. Anal. Chem. 338, 255 (1990)

9. Neelam Goyal, M.J.Kulkarni, S.K.Thulasidas, P. J. Purohit and A.G. Page, Anal. Lett. 32, 3059 (1999).

10. Paru J. Purohit, Neelam Goyal and S. V. Godbole; At. Spectrosc. 32, 68 (2011).

11. A.G. Page, S.V. Godbole, M.J. Kulkarni, N.K. Porwal, S.K. Thulasidas, M.D. Sastry, and P.S. Srinivasan, BARC 1325, 1986). 


\section{Atomic $_{\text {Spectroscopy }}^{\text {to }}$ \\ 1 Vol. 32(3), May/June 2011}

12. N.P. Zaksas, V.A. Gerasimov, and G.A. Nevinsky, Talanta 80, 2187 (2010).

13. B.M. Patel, Neelam Goyal, Paru Purohit, A.R. Dhobale and B.D.Joshi, F.Z.of Anal. Chem. 315, 42 (1983).

14. A. G. Page, S. V. Godbole, M. J. Kulkarni, N. K. Porwal, S. S. Shelar and B. D. Joshi, Talanta 30, 783 (1983).

15. M.Tuzen, K.O. Saygi, and M. Soylak, 2007 Talanta 71, 424 (2007).

16. A. Javadi, S.A. Khatibi, M. Khakpour, M. Ganjali, H. Ghorbanpour, Research Journal of Applied Sciences 4, 185 (2009).

17. K. Sołtyk, A. Łozak, P. Ostapczuk, and Z. Fijałek, Journal of Pharmaceutical and Biomedical Analysis 32 (3), 425 (2003).

18. Z. Fijałek, K. Sołtyk, A. Łozak, A. Kominek, and P.Ostapczuk, Pharmazie 58 (7), 480 (2003).

19. Neelam Goyal, M.J. Kulkarni, S.K. Thulasidas, P.J. Purohit, and A.G. Page, Anal. Lett. 32, 3059 (1999).

20 F. H. Lyra, M. T. W. D.Carneiro, G. P. Brandão, H. M. Pessoa, E. V.de Castro, Microchemical Journal 96, 180 (2010).

21 A. De Jesus, A. V. Zmozinski, J. A. Barbará, M. G. R. Vale, and M. M. Silva, Energy and Fuels 24 (3), 2109 (2010).

22 C. V. S. Ieggli, D.Bohrer, P. C. do Nascimento, and L. M. de Carvalho, Food Chemistry 124 (3), 1189 (2011)

23 X. Cui, Y. Wang, and X. She, Journal of Ocean University of China 9, 235 (2010).

24 I. Sergiel, P. Pohl, Journal of Agricultural and Food Chemistry 58, 7497 (2010).

25 C.V. S. Ieggli, D. Bohrer, P. C. do Nascimento, L. M. de Carvalho, and S. C. Garcia, Talanta 80, 1282 (2010).

26 S. Alves, M. L. Simões Gonçalves, and M. M. Correia Dos Santos, Phytochemical Analysis 20, 365 (2009).
27. J. B. Pereira Jr., K. G. Fernandes, R. C. S. Müller, J. A. Nóbrega, and D. C. Palheta, Quimica Nova 32, 2333 (2009).

28 Z. Kopanski, W. Osikowska, M. Schlegel-Zawadzka, J. Zyznawska, and R. Pieta, Trace Elements and Electrolytes 24, 24 (2007).

29. A.V Zmozinski, A. de Jesus, M. G. R. Vale, and M. M. Silva, Talanta 83, 637 (2010)

30 Y.-J. Xiong, L. Ouyang, Y.-Q. Liu, Q. Xie, H. S. Liu, and J. Y. Wang, Spectroscopy and Spectral Analysis. 26 (11), 2120 (2006).

31. R. E. Sturgeon and C. 1. Chakrabarti, I. S. Maines and P. C. Bentels, Anal. Chem. 47, 1240 (1975).

32. R.E. Sturgeon and C.L. Chakraborty, Prog. in Anal. At. Spectr., 1 (1978) 147.

33. R. E. Sturgeon and C. 1. Chakrabarti and C. E Langford, Anal. Chem. 48, 1792 (1976).

34. T.R.G. Kutty, P.V. Hegde, K.B. Khan, T. Jarvis, A.K. Sengupta, S. Majumdar and H.S. Kamath, J. Nucl. Mat. 334, 462 (2004).

35. B. V. L'vov and L. A. Pelieva, Zavod. Lab. 44(2), 173 (1978).

36. A. A. Pupyshev and A. A. Shtenke, Zh. Prikl. Spektrosk. 33(1), 157 (1980).

37. V. K. Nagdaev and A. A. Pupyshev, Zhurnal Prikladnoi Spektroskopii 36(3), 373 (1982). 